\title{
Successful application of pulsed electromagnetic fields in a patient with post-COVID-19 fatigue: a case report
}

\author{
Barbara Wagner (D) - Margarete Steiner - Lovro Markovic · Richard Crevenna
}

Received: 28 September 2021 / Accepted: 29 November 2021 / Published online: 10 January 2022 (C) The Author(s) 2021

\begin{abstract}
Summary
Background Post-COVID-19 fatigue is a frequent symptom in COVID-19 survivors, which substantially limits patients to achieve full recovery and potentially restrains return to work. The previous literature has not yet reported the use of pulsed electromagnetic fields in this indication.

Methods Over the course of 5 weeks, 10 sessions of pulsed electromagnetic field treatment with a high magnetic flux density were applied to a patient suffering from post-COVID-19 fatigue syndrome. Fatigue, work ability, quality of life as well as anxiety, depression, stress level, and resilience were evaluated using validated patient-reported outcome measures.

Results Fatigue, work ability, quality of life, and psychological well-being improved clearly over the course of the treatment and showed stable results 6 weeks later.

Conclusion The use of pulsed electromagnetic field therapy with a device that allows sufficient penetration of the body tissue might be a promising physical modality to manage post-COVID-19 fatigue syndrome, which could reduce clinical and economic health consequences. Clinical sham-controlled studies are needed to evaluate the effect of pulsed electromagnetic fields in this indication.
\end{abstract}

Keywords Magnetic field therapy · PEMF · Ioninduction therapy $\cdot$ Long COVID syndrome . Rehabilitation

\footnotetext{
Dr. B. Wagner · OR Mag. M. Steiner · Dr. L. Markovic · Univ. Prof. Dr. R. Crevenna, MBA MMSc $(\varangle)$ Department of Physical Medicine, Rehabilitation and Occupational Medicine, Medical University of Vienna, Waehringer Guertel 18-20, 1090 Vienna, Austria richard.crevenna@meduniwien.ac.at
}

Erfolgreiche Anwendung von gepulster Magnetfeldtherapie bei einer Patientin mit PostCOVID-19-Erschöpfungssyndrom: ein Fallbericht

\section{Zusammenfassung}

Grundlagen Das Post-COVID-19-Erschöpfungssyndrom ist ein häufiges Syndrom nach COVID-19, das die vollständige Genesung und möglicherweise auch die Rückkehr in den Arbeitsprozess erheblich einschränkt. In der bisherigen wissenschaftlichen Literatur wurde noch nicht über den Einsatz gepulster Magnetfelder bei dieser Indikation berichtet.

Methodik Eine Patientin, die an einem Post-COVID19 Erschöpfungssyndrom litt, wurde über einen Zeitraum von 5 Wochen mit 10 Einheiten gepulster Magnetfeldtherapie von hoher magnetischer Flussdichte behandelt. Müdigkeit, Arbeitsfähigkeit, Lebensqualität, Ängstlichkeit, Depression, Stressniveau und Resilienz wurden mittels validierter Fragebögen erfasst. Ergebnisse Die Müdigkeit, Arbeitsfähigkeit, Lebensqualität und das psychische Wohlbefinden besserten sich im Verlauf der Behandlung deutlich und zeigten auch 6 Wochen später stabile Ergebnisse.

Schlussfolgerungen Die Anwendung der gepulsten Magnetfeldtherapie mit einem Gerät, das eine ausreichende Eindringtiefe in das Körpergewebe ermöglicht, könnte eine vielversprechende physikalische Methode zur Behandlung des Erschöpfungssyndroms nach COVID-19 sein, um die gesundheitlichen und wirtschaftlichen Folgen der Erkrankung zu reduzieren. Klinische placebokontrollierte Studien sind notwendig, um die Wirkung gepulster Magnetfeldtherapie in dieser Indikation zu erforschen.

Schlüsselwörter Magnetfeldtherapie · PEMF . Ioneninduktionstherapie · Long-COVID-Syndrom . Rehabilitation 


\section{Introduction}

During the SARS-CoV-2 pandemic, more than 218.9 million people worldwide have been infected with the virus. In Austria, there have been more than 687,200 confirmed COVID-19 infections; around 676,600 people were considered to be COVID-19 survivors by the beginning of September 2021 [1]. Post-COVID-19 fatigue syndrome is primarily associated with physical weakness, tiredness, and exhaustion. Fatigue affects roughly $85 \%$ of patients hospitalized due to COVID19 [2] and over $60 \%$ of patients at 5-6 months from symptom onset [3]. Thus, it substantially limits patients ability to achieve full recovery and potentially restrains return to work. Further common physical and mental health sequelae of post-COVID-19 are musculoskeletal pain, reduced physical capacity, anxiety, depression, posttraumatic stress disorder, and overall lower quality of life [4]. There is a need for further research on effective rehabilitation strategies to manage these conditions [3].

Electromagnetic fields can affect biological structures such as body cells and tissues and can induce selective changes in their microenvironment [5]. The effect is athermal [5, 6]. Exposing the body to electromagnetic fields is possible through either capacitive coupling (placing opposite electrodes within a conducting medium) or through inductive coupling (a time-varying pulsed electric field induces an electric current in the target tissue) [5].

To our knowledge, this is the first scientific report in which pulsed electromagnetic field (PEMF) treatment has been applied in the rehabilitation of a patient suffering from post-COVID-19 fatigue syndrome.

\section{Case report}

A 55-year-old female presented with persisting weakness, tiredness, and exhaustion since the infection with SARS-CoV-2 6.5 months ago. COVID-19 disease had initially caused respiratory symptoms, myalgia, cephalea, and anosmia. She had been on sick leave for 3 weeks, taking mefenamic acid (Parkemed ${ }^{\circledR} 500 \mathrm{mg}$ ) twice daily for pain control. At her initial visit to our outpatient clinic, her main complaint was fatigue, which severely affected her workability, along with difficulty in concentrating and persisting exertional dyspnea. Relevant pre-existing conditions were a nodular euthyroid goiter, restless legs syndrome, and climacteric complaints (excessive perspiration). Except for an estrogen drug (17-beta-estradiol, Estrogel $\mathrm{Gel}^{\circledR} 80 \mathrm{~g}$ ) that the gynecologist had prescribed for menopausal symptoms, she took no medication. She was married, had two children, and worked $30 \mathrm{~h}$ a week. Complaints had been aggravated due to heavy mental workload after the sick leave. Another stress factor were periods of homeschooling for her children due to three lockdowns over much of the time until 2 months before PEMF treatment started.
Her height, weight, and body mass index were $177 \mathrm{~cm}, 70 \mathrm{~kg}$, and $22 \mathrm{~kg} / \mathrm{m}^{2}$, respectively. Auscultation of the heart and lungs was normal. Blood pressure was $130 / 80 \mathrm{mmHg}$. Blood values showed a normal hemogram except for minimally decremented leucocytes $(3.69 \mathrm{G} / \mathrm{L})$, and normal CRP, electrolytes, $25-\mathrm{OH}$ vitamin $\mathrm{D}$, iron, liver, and kidney values as well as thyroidal and metabolic parameters. Pulmonologist checkup turned out normal as well.

The patient had not received any treatment for her fatigue symptoms specifically. She had started supervised resistance training for 10 different muscle groups twice weekly 5 months previously. The training involved two sets of 13-15 repetitions and was progressed as strength improved. Subjectively, the training had not changed fatigue symptoms.

\section{Methods}

The patient gave informed consent to receive PEMF to treat fatigue symptoms and to document the findings for a case study. We used the Papimi ${ }^{\mathrm{TM}}$ electromagnetic field therapy device (Pulse Dynamics Ltd., Pipinou 1 \& Souliou, 17342 Agios Dimitrios, Greece), which is a certified and approved medical device (class IIa) that can be safely and effectively applied to treat fatigue and general weakness $[6,7]$. It is based on the principle of ion induction. The Papimi ${ }^{\mathrm{TM}}$ pulse is like a damped oscillation with a short pulse duration of $\sim 50 \mu \mathrm{s}$. The basic frequency is $\sim 240 \mathrm{kHz}$; in the maxima and minima of the damped oscillation, high-frequency oscillation peaks in the megahertz to gigahertz range arise. The pulse rate can be varied between 1 and $8 \mathrm{~Hz}$. High voltages (up to $40 \mathrm{kV}$ ) and peak currents (up to $10 \mathrm{kA}$ ) arise in the applicator spool. As a result, the Papimi ${ }^{\mathrm{TM}}$ device achieves delivery of energy per pulse of about $96 \mathrm{Ws}$ (Joule) with a magnetic flux density of 50-100 $\mathrm{mT}$ [6].

Contraindications to PEMF therapy, which include electronic implants (e.g., pacemaker, implantable cardioverter defibrillator, cochlear implants), pregnancy, and ring-shaped metals in the body [6], were ruled out prior to starting the treatment.

The patient received 10 sessions of PEMF twice weekly for 5 weeks, each session lasting $30 \mathrm{~min}$. The treatment protocol was chosen as follows: starting with the patient supine, $6 \mathrm{~min}$ in the epigastric/ abdominal area, and $3 \mathrm{~min}$ over the sternum were administered. Then, 6 min were applied in the dorsal area (covering the lungs and the adrenal area), $6 \mathrm{~min}$ in the pelvic floor area, and $6 \mathrm{~min}$ on the soles of both feet. Locations of application were chosen following the device manufacturer's manual [8]. The pulse rate was $2.5 \mathrm{~Hz}$ in the dorsal area and $1 \mathrm{~Hz}$ for all other locations. Treatment intensity was adapted as tolerated, choosing the distance between the applicator spool and the patient's skin between 0 and $4 \mathrm{~cm}$. Initially, the smaller treatment spool (diameter $18 \mathrm{~cm}$ ) was used, during the course of the treatment 
Table 1 Questionnaire results pretreatment, posttreatment, and 6 weeks after treatment

\begin{tabular}{|c|c|c|c|c|c|c|}
\hline & \multirow[t]{2}{*}{ Subscales } & \multirow[t]{2}{*}{ Range (points) } & \multirow[t]{2}{*}{ Score interpretation } & \multicolumn{3}{|c|}{ Results (see legend) } \\
\hline & & & & $\mathrm{T} 1$ & T2 & T3 \\
\hline \multirow[t]{10}{*}{ BFI } & BFI total score & \multirow[t]{10}{*}[0-10]{} & \multirow{10}{*}{$\begin{array}{l}\text { Fatigue: } \\
\text { 1-3: mild } \\
\text { 4-6: moderate } \\
\text { 7-10: severe }\end{array}$} & 6.33 & 0.22 & 0.11 \\
\hline & Fatigue right now & & & 7 & 0 & 0 \\
\hline & Usual fatigue in last $24 \mathrm{~h}$ & & & 7 & 1 & 0 \\
\hline & Worst fatigue in last $24 \mathrm{~h}$ & & & 7 & 1 & 1 \\
\hline & General activity & & & 3 & 0 & 0 \\
\hline & Mood & & & 8 & 0 & 0 \\
\hline & Walking ability & & & 0 & 0 & 0 \\
\hline & Normal work (incl. housework) & & & 7 & 0 & 0 \\
\hline & Relations with other people & & & 9 & 0 & 0 \\
\hline & Enjoyment of life & & & 9 & 0 & 0 \\
\hline \multirow[t]{8}{*}{ SF-36 } & Physical functioning & \multirow[t]{8}{*}{ [0-100] } & \multirow{8}{*}{$\begin{array}{l}\text { Quality of life: } \\
\text { 0: worst value } \\
\text { 100: best value }\end{array}$} & 60 & 90 & 90 \\
\hline & Role physical & & & 25 & 100 & 100 \\
\hline & Role emotional & & & 0 & 100 & 100 \\
\hline & Vitality & & & 10 & 85 & 95 \\
\hline & Mental health & & & 44 & 96 & 92 \\
\hline & Social functioning & & & 25 & 87.5 & 100 \\
\hline & Bodily pain & & & 41 & 84 & 84 \\
\hline & General health perceptions & & & 55 & 100 & 100 \\
\hline WAl & WAI (short version) & [7-49] & $\begin{array}{l}\text { Work ability: } \\
\text { 7-27: critical } \\
\text { 28-36: moderate } \\
\text { 37-43: good } \\
\text { 44-49: very good }\end{array}$ & 21.5 & 40 & 40 \\
\hline \multirow[t]{3}{*}{ PSS-10 } & PSS-10 total score & {$[0-50]$} & \multirow{3}{*}{$\begin{array}{l}\text { Stress level (total score): } \\
0-13 \text { : low } \\
\text { 14-26: moderate } \\
\text { 227: high }\end{array}$} & 43 & 16 & 16 \\
\hline & Helplessness & [6-30] & & 27 & 11 & 10 \\
\hline & Self-efficacy & [4-20] & & 8 & 19 & 18 \\
\hline PHQ-9 & PHQ-9 & [0-27] & $\begin{array}{l}\text { Depression: } \\
\text { 5-9: mild } \\
\text { 10-14: moderate } \\
\text { 15-19: moderately severe } \\
\text { 20-27: severe }\end{array}$ & 16 & 2 & 1 \\
\hline GAD-7 & GAD-7 & [0-21] & $\begin{array}{l}\text { Generalized anxiety: } \\
\text { 5-9: mild } \\
\text { 10-14: moderate } \\
\text { 15-21: severe }\end{array}$ & 13 & 2 & 2 \\
\hline BRS & BRS & {$[1-5]$} & $\begin{array}{l}\text { Resilience: } \\
\text { 1.00-2.99: low } \\
\text { 3.00-4.30: normal } \\
\text { 4.31-5.00: high }\end{array}$ & 2.67 & 4.67 & 4.67 \\
\hline
\end{tabular}

the larger spool (diameter $20 \mathrm{~cm}$ ) was applied for all areas except the pelvic floor. Most of the time, $75 \%$ of maximum power was chosen for the abdominal, sternal, and pelvic floor area and $100 \%$ for the dorsal and plantar applications.

Since long COVID-19 syndrome is associated with both physical and mental health issues [4], the following validated patient-reported outcome tools were chosen to evaluate the treatment effect pre- and postintervention (Table 1): The Brief Fatigue Inventory (BFI) measures severity and impairment from fatigue [9]. The Short Form (SF-36) Health Survey is a questionnaire to measure health-related quality of life [10]. The Work Ability Index (WAI) short version evaluates work ability in relation to current physical and psychological work demands [11, 12]. The Perceived Stress Scale (PSS-10) assesses the subjective experience of stress, including the subscales helplessness and self-efficacy [13]. The Patient Health Questionnaire 9 (PHQ-9) is a tool to screen for the presence and severity of depression [14]. The Generalized Anxiety Disorder 7 (GAD-7) is a questionnaire to identify patients with a generalized anxiety disorder and capture the severity of symptoms [15, 16]. The Brief Resilience Scale (BRS) measures the ability 
to successfully cope with difficult, stressful situations and to recover quickly from them $[17,18]$.

\section{Results}

The patient reported an increase in energy and a decrease of fatigue symptoms as of the fourth treatment session, with improvements continuing over the following sessions. After completing all 10 sessions, she felt fully recovered and able to face challenges in work and private life. Wellbeing continued at the follow-up evaluation 6 weeks later. No significant side effects had occurred apart from an increase in neck pain during local PEMF application, which disappeared after adapting treatment intensity in this specific area, and a short-term increase in fatigue after the first session.

The results of all questionnaires that were administered before (T1), immediately after (T2), and 6 weeks (T3) after the end of the treatment reflected the patient-reported outcome (Table 1). The BFI score decreased from 6.33 (moderate fatigue) at baseline to 0.22 (no fatigue) post intervention. The largest improvements were seen in the dimensions of mood, work, relationship, and enjoyment of life. The SF36 also showed an increase in several dimensions. Workability improved from critical (21.5 points) before treatment to good (40 points) after the intervention. The pre-intervention total score of the PSS10 decreased from a high (43 points) to a moderate (16 points) stress level post intervention. The value for the subscale helplessness decreased from 27 to 11 points and, on the other hand, the value for self-efficacy increased from 8 to 19 points. The PHQ-9 score improved from 16 points (indicating moderately severe depression) to a normal level (2 points). The GAD-7 score also decreased from a pathologic (13 points) to a normal value ( 2 points) during the treatment. Resilience level improved from low (2.67 points) to high (4.67 points) after treatment. Improvements persisted in all areas, as the follow-up evaluation showed 6 weeks later. To give us examples of her new energy levels, the patient reported that 3-h hikes or baking a cake at the end of a busy day were no longer a problem.

\section{Discussion}

In patients suffering from fatigue, PEMF treatment has been applied primarily in patients with multiple sclerosis, with mixed success [19-27].

Similarly, randomized controlled trials (RCTs) on magnetic therapy in fibromyalgia patients showed mixed results: in one trial, PEMF mat therapy improved pain, fibromyalgia impact questionnaire, and quality of life compared to placebo [28], whereas another study showed no superiority of PEMF over placebo in improving pain and function [29]. In chronic musculoskeletal pain (including fibromyalgia patients), PEMF had no significantly differential ad- vantage over sham treatment [30]. Regarding static magnetic devices, mattress pads during sleep provided statistically significant pain relief and sleep improvement [31], whereas another trial found low static magnetic fields only superior to sham/usual care in terms of decreased pain levels [32]. Repetitive transcranial magnetic brain stimulation relieved pain and enhanced quality of life in patients with fibromyalgia but did not improve other symptoms, as shown in a recent systematic review [33].

In workers with work-related chronic stress, an RCT found no additional effect of light plus PEMF therapy on return to work, fatigue, stress, and quality of life compared to coaching alone [34].

However, low-frequency PEMF therapy has already been used successfully in a Russian study in the rehabilitation of 52 patients after COVID-19 pneumonia. PEMF decreased respiratory symptoms, pain, anxiety, and depression, and improved quality of life [35].

The particular physical parameters of the applied electromagnetic fields appear to have a significant impact on the observed effect on biologic structures. Devices with short pulse duration and a wide frequency spectrum may provide a higher chance of activating cellular reactions [5]. The particular physical parameters of electromagnetic devices have to be considered when studies are compared and results are interpreted [5]. Unfortunately, necessary details characterizing an electromagnetic device such as the type of the field, the intensity of the induction, frequency, pulse rate of rise and decline, pulse shape, and vector or time of exposure are rare information even in scientific publications and vary greatly among different treatment protocols. Therefore, comparisons between existing studies and qualified ratings are often difficult [5]. Many of the previous studies on multiple sclerosis-associated fatigue [20-27] and on fibromyalgia [28-30, 32] were performed with magnetic flux densities in the microtesla range, using very heterogeneous treatment parameters. Therefore, these protocols are hardly comparable to the one used in this case.

This single case study showed promising results upon applying PEMF in a patient suffering from postCOVID-19 fatigue. The literature reports associations between physical symptoms and mental health issues such as anxiety and depression [4]. Our results can similarly be interpreted to the effect that an improvement in the physical energy level appears to have a clear influence on psychological wellbeing and resilience.

The exact mode of action of electromagnetic fields is unknown [5]. Among other hypotheses, it is suggested that electromagnetic stimuli interact with cells via either ion channels or transmembrane receptors, thereby initiating signal transduction cascades or modifying cellular functions [5, 36]. Brief exposure to low millitesla-range PEMF was recently shown to enhance mitochondriogenesis [37] and modulate metabolism and gut microbiome [38] in 
a cell study and animal experiment. The gut microbiome-immune system-brain axis is, in turn, sensitive to stress and plays an important role in the development of stress-related symptoms such as a major depressive disorder [39], which might explain the benefit of the PEMF application on certain psychological parameters.

A limitation of this case report could be that factors other than PEMF may have contributed to an improvement in symptoms. Physical exercise, particularly aerobic plus resistance training, can improve cancer-related fatigue [40]. However, the patient started physical exercise 5 months before PEMF therapy and had not seen any subjective improvement on fatigue until then. Up to 2 months before the start of PEMF treatment there was homeschooling. Psychological factors such as her decision to enhance self-care and reduce weekly working hours in the future may also have played a role. However, it can be assumed that an improvement of the individual parameters to this extent over a treatment period of only 5 weeks would not have been expected without intervention, considering that the complaints had already persisted for 6.5 months.

Magnetic field therapy based on ion induction therapy is well tolerated, noninvasive, and easily applied to the fully dressed patient [5]. According to manufacturer specifications of the Papimi ${ }^{\mathrm{TM}}$ device, dizziness, fatigue, nausea, or headache (in $1.5 \%$ of those treated) may occur after the first treatment as well as a shortterm worsening of the initial symptoms [6]. The literature does not report any significant side effects from PEMF treatment $[36,41]$.

Since this application of PEMF in post-COVID-19 fatigue syndrome showed promising results, we aim to evaluate the effect of PEMF on both patient-reported and physical performance outcomes in a larger patient sample. If the results are appropriate, magnetic field therapy could be an important treatment option in addition to physical exercise in the rehabilitation of patients with post-COVID-19 fatigue syndrome. It may also serve as a treatment strategy on its own in patients with contraindications to physical exercise or significant limitations due to underlying cardiopulmonary or orthopedic diseases.

\section{Conclusion}

Post-COVID-19 fatigue is a frequent symptom that currently affects many COVID-19 survivors. PEMF is well tolerated, easy to apply, and has shown promising results in this case study. The use of PEMF therapy with a device that allows sufficient penetration of the body tissue might be a promising physical modality to manage post-COVID-19 fatigue and associated symptoms, which could reduce economic and clinical health consequences. Clinical sham-controlled studies are needed to evaluate the effect of PEMF on patients with post-COVID-19 fatigue syndrome. At- tention should be paid to an exact specification of the physical characteristics of the respective PEMF device and the description of the treatment protocol, so that studies are comparable and study data can be interpreted correctly.

Acknowledgements The authors thank Prim. Dr. Gerhard Fürst who provided expert advice in the establishment of the PEMF treatment concept.

Author Contribution All authors contributed equally to the manuscript and read and approved the final version of the manuscript.

Funding Open access funding provided by Medical University of Vienna.

Conflict of interest B. Wagner, M. Steiner, L. Markovic, and R. Crevenna declare that they have no competing interests.

Open Access This article is licensed under a Creative Commons Attribution 4.0 International License, which permits use, sharing, adaptation, distribution and reproduction in any medium or format, as long as you give appropriate credit to the original author(s) and the source, provide a link to the Creative Commons licence, and indicate if changes were made. The images or other third party material in this article are included in the article's Creative Commons licence, unless indicated otherwise in a credit line to the material. If material is not included in the article's Creative Commons licence and your intended use is not permitted by statutory regulation or exceeds the permitted use, you will need to obtain permission directly from the copyright holder. To view a copy of this licence, visit http://creativecommons.org/licenses/by/4.0/.

\section{References}

1. WHO. WHO coronavirus disease (COVID-19) dashboard. 2021. https://covid19. who.int/. Accessed6Sept 2021.

2. Tuzun S, Keles A, Okutan D, et al. Assessment of musculoskeletal pain, fatigue and grip strength in hopitalized patients with COVID-19. Eur J Phys Rehabil Med. 2021; https://doi.org/10.23736/S1973-9087.20.06563-6.

3. Negrini F, de Sire A, Andrenelli E, et al. Rehabilitation and COVID-19: update of the rapid living systematic review by Cochrane Rehabilitation Field as of April 30th, 2021. Eur J Phys Rehabil Med. 2021; https://doi.org/10.23736/S19739087.21.07125-2.

4. Shanbehzadeh S, Tavahomi M, Zanjari N, et al. Physical and mental health complications post-COVID-19: Scoping review. JPsychosom Res. 2021;147:110525. https://doi.org/ 10.1016/j.jpsychores.2021.110525.

5. Bachl N, Ruoff G, Wessner B, et al. Electromagnetic interventions in musculoskeletal disorders. Clin Sports Med. 2008;27(1):87-105. https://doi.org/10.1016/j.csm. 2007.10.006.

6. Papimi ${ }^{\circledR}$ official homepage. Papimi therapy—products. 2021. https:// papimi-therapie.eu/. Accessed 23 May 2021.

7. Pappas T, Vlismas N, Papadimitrakopoylos J, et al. Clinical evaluation report papimi ${ }^{\mathrm{TM}}$ series, version 1.2012. Issue 1.

8. Papimi ${ }^{\circledR}$ manual. Experiences of application. Version 05.2019.

9. Radbruch L, Sabatowski R, Elsner F, et al. Validation of the German version of the brief fatigue inventory. J Pain Symptom Manage. 2003; https://doi.org/10.1016/s08853924(03)00073-3.

10. Morfeld M, Kirchberger I, Bullinger M. Fragebogen zum Gesundheitszustand: Deutsche Version des Short Form-36 
Health Survey. 2011. https://www.testzentrale.de/shop/ fragebogen-zum-gesundheitszustand.html. Accessed 19 Nov2021.

11. Van den Berg TIJ, Elders LAM, de Zwart BCH, et al. The effects of work-related and individual factors on the work ability index: a systematic review. Occup Environ Med. 2009;66(4):211-20. https://doi.org/10.1136/oem. 2008.039883.

12. WAI Netzwerk. Wie steht es um Ihre Arbeitsfähigkeit? WAI-Fragebogen \& Auswertung (Kurzversion) 2017. 2017. https://www.arbeitsfaehig.com/uploads/z-neue Uploads/WAI-Netzwerk/WAI-Fragebogen-Kurzversion mitAuswertungsbogen.pdf. Accessed 23 May 2021.

13. Klein EM, Brähler E, Dreier M, et al. The German version of the perceived stress scale-Psychometric characteristics in a representative German community sample. BMC Psychiatry. 2016;16(1):159. https://doi.org/10.1186/s12888-0160875-9.

14. Kroenke K, Spitze RL, Williams JBW. The PHQ-9: validity of a brief depression severity measure. J Gen Intern Med. 2001;16(9):606-13. https://doi.org/10.1046/j.1525-1497. 2001.016009606.x.

15. Löwe B, Decker O, Müller S. Validation and standardization of the generalized anxiety disorder screener (GAD-7) in the general population. Med Care. 2008;46(3):266-74. https:// doi.org/10.1097/MLR.0b013e318160d093.

16. Spitzer RL, Kroenke K, Williams JBW, et al. A brief measure for assessing generalized anxiety disorder: the GAD-7. Arch Intern Med. 2006;166(10):1092-7. https://doi.org/10. 1001/archinte.166.10.1092.

17. ChmitorzA, Wenzel M, Stieglitz RD, et al. Population-based validation of a German version of the brief resilience scale. PLoS ONE. 2018;13(2):192761. https://doi.org/10.1371/ journal.pone.0192761.

18. Kunzler AM, ChmitorzA, Bagusat C, et al. Construct validity and population-based norms of the German brief resilience scale (BRS). Eur J Heal Psychol. 2018;25(3):107-17. https:// doi.org/10.1027/2512-8442/a000016.

19. Hochsprung A, Escudero-Uribe S, Ibáñez-Vera AJ, et al. Effectiveness of monopolar dielectric transmission of pulsed electromagnetic fields for multiple sclerosis-related pain: a pilot study. Neurologia. 2018; https://doi.org/10.1016/j. nrleng.2018.03.003.

20. Haase R, Piatkowski J, Ziemssen T. Long-term effects of bioelectromagnetic-energy regulation therapy on fatigue in patients with multiple sclerosis. Altern Ther Health Med. 2011;17(6):22-8.

21. Neill J, Belan I, Ried K. Effectiveness of non-pharmacological interventions for fatigue in adults with multiple sclerosis, rheumatoid arthritis, or systemic lupus erythematosus: a systematic review. JAdv Nurs. 2006;56(6):617-35. https:// doi.org/10.1111/j.1365-2648.2006.04054.x.

22. Richards TL, Lappin MS, Acosta-Urquidi J. Double-blind study of pulsing magnetic field effects on multiple sclerosis. JAltern ComplementMed. 1997;3(1):21-9. https://doi.org/ 10.1089/acm.1997.3.21.

23. Lappin MS, Lawrie FW, Richards TL, et al. Effects of a pulsed electromagnetic therapy on multiple sclerosis fatigue and quality of life: a double-blind, placebo controlled trial. Altern Ther Health Med. 2003;9(4):38-48.

24. Mostert S, Kesselring J. Effect of pulsed magnetic field therapy on the level of fatigue in patients with multiple sclerosis--A randomized controlled trial. Mult Scler. 2005;11(3):302-5.

25. Sandyk R. Treatment with weak electromagnetic fields improves fatigue associated with multiple sclerosis. Int $\mathrm{J}$ Neurosci. 1996;84(1-4):177-86.
26. Sandyk R. Immediate recovery of cognitive functions and resolution of fatigue by treatment with weak electromagnetic fields in a patient with multiple sclerosis. Int J Neurosci. 1997;90(1-2):59-74.

27. PiatkowskiJ, Kern JS,Ziemssen T.Effect of BEMER magnetic field therapy on the level of fatigue in patients with multiple sclerosis: a randomized, double-blind controlled trial. JAltern Complement Med. 2009;15(5):507-11.

28. Sutbeyaz ST, Sezer N, Koseoglu F. Low-frequency pulsed electromagnetic field therapy in fibromyalgia: a randomized, double-blind, sham-controlled clinical study. Clin J Pain. 2009;25(8):722-8.

29. Multanen J, Häkkinen A, Heikkinen P, et al. Pulsed electromagnetic field therapy in the treatment of pain and other symptoms in fibromyalgia: A randomized controlled study. Bioelectromagnetics. 2018;39(5):405-13.

30. Thomas AW, Graham K, Prato FS. A randomized, doubleblind, placebo-controlled clinical trial using a low-frequency magnetic field in the treatment of musculoskeletal chronic pain. Pain Res Manag. 2007;12(4):249-58.

31. Colbert AP, Markov MS, Banerji M, et al. Magnetic mattress pad use in patients with fibromyalgia: a randomized double-blind pilot study. J Back Musculoskelet Rehabil. 1999;13(1):19-31.

32. Alfano AP, Taylor AG, Foresman PA, et al. Static magnetic fields for treatment of fibromyalgia: a randomized controlled trial. JAltern Complement Med. 2001;7(1):53-64.

33. Sun P, FangL, ZhangJ, etal. Repetitive transcranialmagnetic stimulation for fibromyalgia patients: a systematic review with meta-analysis. Pain Med. 2021; https://doi.org/10. 1093/pm/pnab276.

34. Nieuwenhuijsen K, Schoutens AMC, Frings-Dresen MHW, et al. Evaluation of a randomized controlled trial on the effect on return to work with coaching combined with light therapy and pulsed electromagnetic field therapy for workers with work-related chronic stress. BMC Public Health. 2017;17(1):761.

35. Bodrova RA, Kuchumova TV, Zakamyrdin AD, et al. Efficacy oflow-frequency magnetic therapyin patients with COVID19 pneumonia. Vopr Kurortol Fizioter I Lech Fiz Kul'tury. 2020;97(6):11.

36. Hug K, Röösli M. Therapeutic effects of whole-body devices applying pulsed electromagnetic fields (PEMF): a systematic literature review. Bioelectromagnetics. 2012;33(2):95-105.

37. Yap JKY, Tai YK, Fröhlich J, et al. Ambient and supplemental magnetic fields promote myogenesis via a TRPC1mitochondrial axis: evidence of a magnetic mitohormetic mechanism. FASEB J. 2019;33(11):12853-72.

38. Tai YK, NgC, PurnamawatiK, etal. Magneticfields modulate metabolism and gut microbiome in correlation with Pgc-1 $\alpha$ expression: Follow-up to an in vitro magnetic mitohormetic study. FASEB J. 2020;34(8):11143-67.

39. Foster JA, Baker GB, Dursun SM. The relationship between the gut microbiome-immune system-brain axis and major depressive disorder. Front Neurol. 2021;12:721126. https:/ / doi.org/10.3389/fneur.2021.721126.

40. Campbell KL, Winters-Stone KM, Wiskemann J. Exercise guidelines for cancer survivors: consensus statement from international multidisciplinary roundtable. Med Sci Sports Exerc. 2019;51(11):2375-90.

41. Li S, Yu B, Zhou D, et al. Electromagnetic fields for treating osteoarthritis. Cochrane Database Syst Rev. 2013; https:// doi.org/10.1002/14651858.CD003523.pub2.

Publisher's Note Springer Nature remains neutral with regard to jurisdictional claims in published maps and institutional affiliations. 